present in all. ${ }^{5}$ In our patients there was evidence of previous tuberculosis, with calcified hilar nodes and peripheral foci, but no evidence of cavitation or active disease in the chest (table). One of our five patients had a single enlarged supraclavicular node, but there was no evidence of any other site being affected. All the patients were Asian, and in none was tuberculosis suspected as a possible diagnosis; in only two was either pus or a biopsy specimen cultured for tuberculosis, and in only two was a tuberculin test done. Our experience suggests that tuberculosis should be considered as a possible diagnosis in Asian patients presenting with a breast lump or abscess, with or without evidence of tuberculosis elsewhere. We suggest that in these patients pus and biopsy specimens from the breast should always be cultured for tuberculosis and that tuberculin testing and chest $x$ ray examination should be used as part of the preoperative assessment.

We thank Mr R J Earlam and Mr A W Goode for permission to report on patients under their care.

${ }^{1}$ Cooper AP. Introductory observations on the diseases of the breast. London: Longman, Rees, and Co, 1829:73-5.

${ }^{2}$ Morgen M. Tuberculosis of the breast. Surg Gynecol Obstet 1931;53: 593-605.

${ }^{3}$ Alagaratnam TT, Ong GB. Tuberculosis of the breast. Br f Surg 1980; 67:125-6.

' Bahadur P, Aurora AL, Sibbal RN, Prabhu SS. Tuberculosis of mammary gland. F Indian Med Assoc 1983;80:8-12.

5 Mukerjee P, Cohen RV, Niden AH. Tuberculosis of the breast. Am Rev Respir Dis 1971;104:661-7.

(Accepted 23 February 1984)

The London Hospital, London E1 $1 \mathrm{BB}$

M C P APPS, MA, MRCP, senior registrar in medicine

N K HARRISON, MA, MRCP, registrar in medicine

C I A BLAUTH, BSC, FRCS, registrar in surgery

Correspondence to: Dr M C P Apps.

\section{Smoking and insulin absorption from subcutaneous tissue}

Klemp et al presented data suggesting decreased absorption of subcutaneously injected short acting insulin during and after smoking a cigarette. ${ }^{1}$ They used an indirect method measuring the decay of radiation over the injection site of radioiodinated insulin, whichamong other hypotheses-assumes that insulin is not degraded at the injection site. ${ }^{2}$ Ample evidence has been presented that a significant amount of exogenous insulin is degraded at the site of injection. ${ }^{3}$ Thus the indirect method used by Klemp et al is not suitable for assessing circulating concentrations of exogenous insulin after subcutaneous injection. Simple direct methods are available to investigate the absorption kinetics of subcutaneously injected insulin in normal people as well as in diabetic patients. ${ }^{34}$ Furthermore, these methods do not require the injection of iodinated material to obtain results.

Since the suggested decrease of more than $100^{\circ}$ in the rate of absorption of subcutaneously injected insulin during cigarette smoking ${ }^{1}$ might be of considerable clinical importance for some diabetic patients, we have investigated the possible influence of smoking on insulin absorption using a direct method to monitor insulin pharmacokinetics.

\section{Subjects, methods, and results}

Experiments were carried out on eight healthy male habitual smokers (age 20-30 years) of normal weight after a 12 hour overnight fast and abstention from smoking. Throughout the experiments, which started at 0800 , the subjects rested supine at a constant room temperature and abstained from food and drink. Blood was taken from a cubital vein for determinations of blood glucose (Beckman glucose analyser) and serum insulin and $C$ peptide concentrations, as described. ${ }^{4}$

All eight subjects took part in the following four experiments, which were carried out in random order over 10 days; in each case insulin was injected subcutaneously into the front of the thigh: (1) $10 \mathrm{U}$ neutral insulin (Velosulin; Nordisk) without smoking, (2) $10 \mathrm{U}$ neutral insulin with smoking, (3) $16 \mathrm{U}$ Mixtard insulin (Nordisk; a mixture of $30 \%$ neutral and $70 \%$ isophane insulin) without smoking, (4) $16 \mathrm{U}$ Mixtard insulin with smoking.

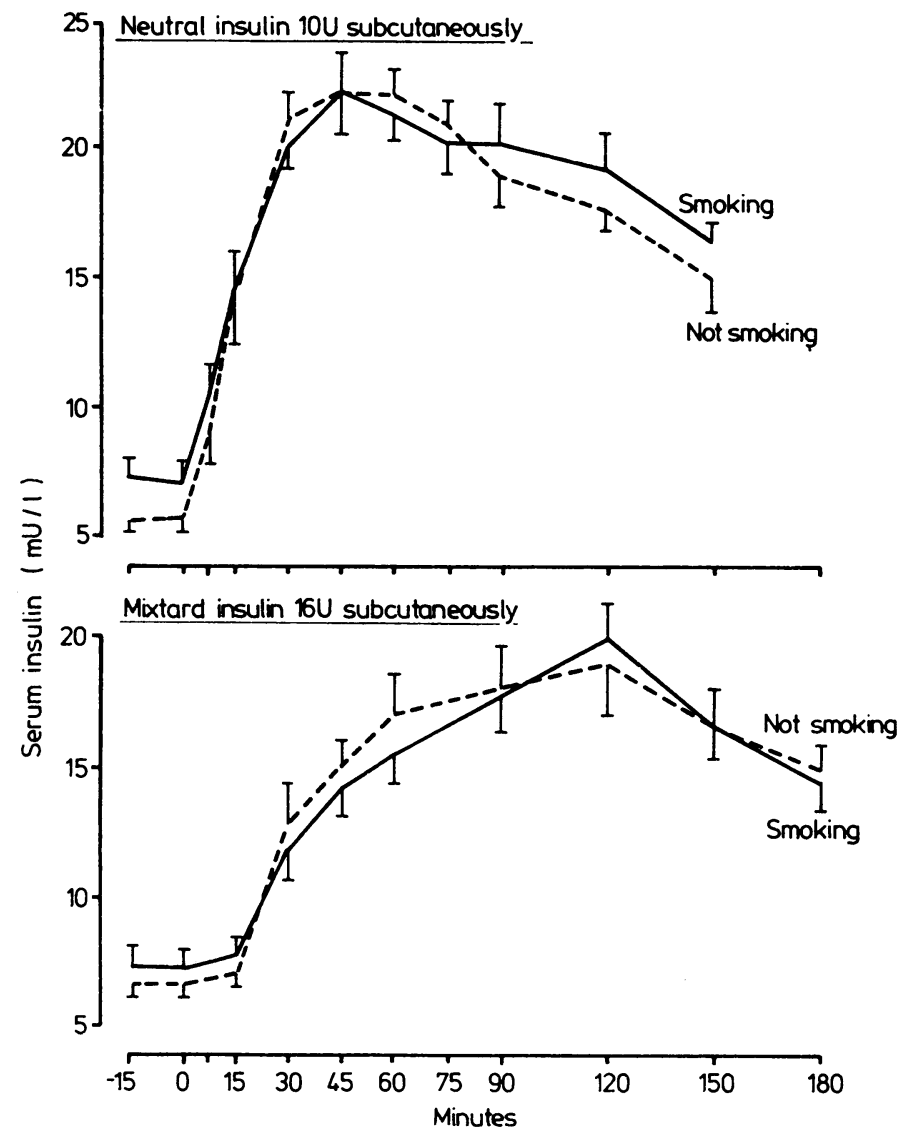

Mean serum concentrations of insulin during each experiment $(n=8)$. Bars are SEM.

In the smoking experiments each subject smoked two cigarettes (filter tipped, $0.9 \mathrm{mg}$ nicotine each), beginning at time points zero and 7.5 minutes. Insulin was injected at 2.5 minutes using a $1 \mathrm{ml}$ Plastipak syringe (Becton Dickinson). All injections were given by the same person (HJC), and great care was taken to keep the conditions of the injection technique constant. During the experiments with neutral insulin blood was taken at $-15,0$, $7 \cdot 5,15,30,45,60,75,90,120$, and 150 minutes, and during the experiments with Mixtard insulin blood was taken at $-15,0,15,30,45,60,90,120,150$, and 180 minutes.

Statistical evaluation of differences was by Student's $t$ test for paired comparison. Results are given as means and SEM.

Throughout the study serum insulin, $C$ peptide, and blood glucose concentrations showed virtually no difference with and without smoking. The figure shows the serum insulin concentrations. In the experiments with neutral insulin blood glucose values decreased from a basal $4 \cdot 6$ (SEM 0.2) $\mathrm{mmol} / 1(82(\mathrm{SEM} \mathrm{3}) \mathrm{mg} / 100 \mathrm{ml})$ without smoking and $4.8(0.1) \mathrm{mmol} / 1$ $(86(2) \mathrm{mg} / 100 \mathrm{ml})$ with smoking to a minimum of $3 \cdot 1(0.2) \mathrm{mmol} / 1$ (56 (4) $\mathrm{mg} / 100 \mathrm{ml}$ ) without smoking and $3.3(0.2) \mathrm{mmol} / 1(60(3) \mathrm{mg} / 100 \mathrm{ml})$ with smoking at 90 minutes. Serum $C$ peptide concentrations decreased from a basal 1.1 (SEM 0.1$) \mu \mathrm{g} / 1$ without smoking and $1.2(0.1) \mu \mathrm{g} / 1$ with smoking to a minimum of $0.2(0 \cdot 1) \mu \mathrm{g} / 1$ without smoking and $0 \cdot 2(0 \cdot 1) \mu \mathrm{g} / 1$ with smoking at 150 minutes.

In the experiments with Mixtard insulin blood glucose values fell from $4.7(0 \cdot 1) \mathrm{mmol} / 1(85(2) \mathrm{mg} / 100 \mathrm{ml})$ without smoking and $4 \cdot 7(0 \cdot 1) \mathrm{mmol} / \mathrm{l}$ (85 (2) $\mathrm{mg} / 100 \mathrm{ml}$ ) with smoking to a minimum of $3 \cdot 3(0 \cdot 1) \mathrm{mmol} / 1(59$ (2) $\mathrm{mg} / 100 \mathrm{ml}$ ) without smoking and $3 \cdot 2(0 \cdot 1) \mathrm{mmol} / \mathrm{l}(58(2) \mathrm{mg} / 100 \mathrm{ml})$ with smoking at 150 minutes. $C$ peptide concentrations decreased from $1 \cdot 2$ $(0.2) \mu \mathrm{g} / 1$ without smoking and $1.0(0 \cdot 2) \mu \mathrm{g} / 1$ with smoking to a minimum of $0.2(0.1) \mu \mathrm{g} / 1$ without smoking and $0.2(0.1) \mu \mathrm{g} / 1$ with smoking at 180 minutes.

\section{Comment}

These results show that in habitual smokers smoking has no acute effect on the absorption of subcutaneously injected insulin. By contrast with the study of Klemp et al ${ }^{1}$ our subjects smoked one cigarette two and a half minutes before and one five minutes after the insulin injection, aiming at stable and high concentrations of nicotine in the circulation during the time of maximal insulin absorption from the subcutaneous tissue. As a consequence of our study, diabetic patients need not consider smoking a cigarette a relevant factor influencing insulin absorption from the subcutaneous tissue. Insulin absorption studies based on controversial indirect methods and using 
radioisotopes should be discouraged since their results could repeatedly not be confirmed when a straightforward system to measure insulin pharmacokinetics was employed. ${ }^{45}$

We thank $\mathrm{K} J$ Klingebiel and $\mathrm{P}$ Könings for their valuable cooperation during the experiments and $\mathrm{C}$ Broermann for her excellent technical work.

${ }^{1}$ Klemp P, Staberg B, Madsbad S, Kolendorf K. Smoking reduces insulin absorption from subcutaneous tissue. Br Med $\mathcal{F}$ 1982;284:237.

2 Binder C. Absorption of injected insulin. Acta Pharmacol Toxicol (Copenh) $1969 ; 27$ (suppl 2):1-84.

${ }^{3}$ Berger M, Cüppers HJ, Hegner H, Jörgens V, Berchtold P. Absorption kinetics and biologic effects of subcutaneously injected insulin preparations. Diabetes Care 1982;5:77-91.

${ }^{4}$ Kemmer FW, Berchtold P, Berger M, et al. Exercise-induced fall of blood glucose unrelated to alteration of insulin mobilisation. Diabetes $1980 ; 28: 1131-7$.

${ }^{5}$ Cüppers HJ, Berchtold P, Berger M. Sauna-induced acceleration in insulin absorption? Br Med f 1982;281:307.

(Accepted 17 April 1984)

Department of Medicine E, University of Düsseldorf, West Germany

I MUHLHAUSER, MD, research assistant

H J CUPPERS, MD, senior registrar

$M$ BERGER, $M D$, professor of medicine

Correspondence to: $\mathrm{Dr}$ Ingrid Mühlhauser, Medizinische Klinik E Universität Düsseldorf, Moorenstrasse 5, 4000 Düsseldorf, West Germany.

\section{Unusual pulmonary reaction during short term prophylaxis with pyrimethamine-sulfadoxine (Fansidar)}

Fansidar (25 mg pyrimethamine and $500 \mathrm{mg}$ sulfadoxine) is a valuable alternative for treating chloroquine resistant falciparum malaria and is increasingly used for prophylaxis. The manufacturer claims that side effects are generally mild and transient. Serious reactions affecting the skin and mucous membranes, liver, and bone marrow have recently been reported, ${ }^{2}{ }^{2}$ but we describe here for the first time pulmonary adverse reactions during pyrimethaminesulfadoxine prophylaxis.

\section{Case report}

A 45 year old man with no history of allergic reactions travelled to Lima, Peru, on 14 October 1982, returning to Sweden four days later. He used pyrimethamine-sulfadoxine (Fansidar) 1 tablet/week for malaria prophylaxis from 29 September to 11 November. The day he left Peru he felt feverish and had a sore throat. After arrival in Sweden he was tired and had a temperature of $38^{\circ} \mathrm{C}$. He then developed cough and transient diarrhoea and from 24 October to 8 November was treated with doxycycline. On 8 November because of his persistent symptoms a chest $x$ ray examination was performed, which showed extensive, subpleural, localised, confluent alveolar infiltrates in the periphery of the lungs. The central parts were normal. Treatment was changed to erythromycin, but this was stopped after six days because it had no effect, and the patient was admitted to hospital on 16 November. Physical examination, including auscultation of the lungs, showed no abnormalities. A second chest radiograph, 10 days after the first, showed slight progression of the pulmonary infiltrates. Laboratory findings were as follows: erythrocyte sedimentation rate $85 \mathrm{~mm}$ in the first hour, haemoglobin $12.6 \mathrm{~g} / \mathrm{dl}$, white blood cell count $8.9 \times 10^{9} / 1$ with $72 \%$ neutrophils and $6 \%$ eosinophils, C reactive protein positive, antinuclear factors not detected. Liver function tests (normal range within brackets) showed bilirubin $6 \mu \mathrm{mol} / \mathrm{l}(4-22 \mu \mathrm{mol} / \mathrm{l})$, aspartate aminotransferase $2.8 \mu \mathrm{kat} / \mathrm{l}(<0.70 \mu \mathrm{kat} / \mathrm{l})$, alanine aminotransferase $3.74 \mu \mathrm{kat} / 1(<0.70 \mu \mathrm{kat} / \mathrm{l})$, and lactate dehydrogenase $7 \cdot 3 \mu \mathrm{kat} / 1(3 \cdot 9-8 \cdot 0 \mu \mathrm{kat} / \mathrm{l})$. Throat cultures showed $\beta$ haemolytic streptococci group A; other cultures were negative. Microscopical examination of sputum, for tuberculosis and parasites, and of stools was negative. Serological tests for various bacteria, viruses, or funguses also yielded negative results.

In view of the throat culture findings we treated him for seven days with phenoxymethylpenicillin. His temperature of $38^{\circ} \mathrm{C}$ persisted until four days after the end of treatment. During his stay in hospital the serum aminotransferase activities rose slightly; the eosinophil count rose to $9 \%$ and the absolute eosinophil count from 300 to $600 \times 10^{6} / 1$. The subsequent course was uneventful and he was discharged on 3 December. Chest $x$ ray findings returned to normal in early January 1983, as did all laboratory values except for aminotransferase activities, which remained abnormal until early May.

\section{Comment}

Various sulphonamides may cause acute pulmonary reactions with fever and transient eosinophilia. Chest radiographs show segmental or diffuse micronodular pulmonary infiltrations. ${ }^{34}$ Most reports, however, have dealt with a combination of trimethoprim and sulfamethoxazole. $^{5}$ Up to November 1983 no similar pulmonary symptoms attributed to pyrimethamine-sulfadoxine were known to the Swedish adverse drug reactions advisory committee. After submitting this report, however, we learnt that one similar case had been reported to the manufacturers of Fansidar in January 1984.

The timing of the symptoms in our patient together with the signs of an allergic reaction suggested that pyrimethamine-sulfadoxine caused the pulmonary reaction and the increase in aminotransferase activities. The patient was not taking any other drugs and the results of extensive microbiological and serological examinations were negative. Definite proof would, however, have required rechallenge with pyrimethamine-sulfadoxine, which we considered unethical.

An increasing number of travellers visit areas where chloroquine resistant falciparum malaria is endemic and where pyrimethaminesulfadoxine is the drug of choice for malaria prophylaxis. We want to warn that pulmonary reactions might be caused by this drug.

1 Westergaard OW, Loft $S$, Dencker CK. Serious reactions during malaria prophylaxis with pyrimethamine-sulfadoxine. Lancet 1982 ;i :994.

2 Whitfield D. Presumptive fatality due to pyrimethamine-sulfadoxine. Larcet $1982 ;$;i : 1272 .

${ }^{3}$ Davies DM. Textbook of adverse drug reactions. Oxford: Oxford University Press, 1981.

- Meyler L, Herxheimer A. Side effects of drugs. Amsterdam: Elsevier, 1980.

${ }^{5}$ Finlayson WB, Johnson G. Multisystem toxicity after co-trimoxazole. Lancet 1978;ii:682-3.

(Accepted 7 March 1984)

Department of Infectious Diseases, Roslagstull Hospital, Karolinska Institute, Stockholm, Sweden

$M$ SVANBOM, MD, physician

L ROMBO, MD, physician

Department of Clinical Pharmacology, Huddinge Hospital, Karolinska Institute, Stockholm, Sweden

L GUSTAFSSON, MD, clinical pharmacologist

Correspondence to: Dr Maj Svanbom, Department of Infectious Diseases, Roslagstull Hospital, Box 5651, S-114 89 Stockholm, Sweden.

\section{Bilateral vocal cord paralysis due to whiplash injury}

Whiplash injuries to the neck are common but they rarely cause major disabilities. We describe a patient who developed bilateral vocal cord paralysis and bilateral lateral rectus palsies after an acceleration injury to her neck-two complications of the whiplash syndrome not previously reported.

\section{Case report}

A 65 year old woman was admitted to hospital in January 1982 after the rear of her car had been struck by another vehicle. She was wearing a seatbelt and did not strike her head but she did sustain a severe whiplash injury to her neck followed by transient loss of consciousness lasting several minutes. Her immediate symptoms were neck and chest pain and diplopia. She had tachycardia (112 beats/min), stridor, weak phonation, and neurological examination showed bilateral sixth nerve palsies. Skull and chest radiographs were normal, but radiographs of the cervical spine showed congenital fusion of the second and third vertebrae. There was no displacement or bone injury and the odontoid process was intact.

She was given a soft collar and admitted for observation. A full ophthalmological examination confirmed bilateral lateral rectus palsies, more pronounced on the left side than the right. Because of the persistent stridor, difficulty in coughing, and weak voice, a laryngoscopy was also performed. This showed the vocal cords to be immobile in the paramedian plane. Examination of the pharynx and postnasal space showed them to be normal. 